\title{
Antiplatelet therapy in acute coronary syndromes: current agents and impact on patient outcomes
}

This article was published in the following Dove Press journal:

Patient Related Outcome Measures

6 January 2011

Number of times this article has been viewed

\author{
Hussam M Tayeb \\ Adam J Nelson \\ Scott R Willoughby \\ Matthew I Worthley \\ Cardiovascular Research Centre, \\ Royal Adelaide Hospital and Discipline \\ of Medicine, University of Adelaide, \\ Adelaide, South Australia, Australia
}

\begin{abstract}
Platelets play a central role in atherothrombosis and subsequent development of acute coronary syndromes (ACS). The understanding of this process has driven a large body of evidence demonstrating the mortality and morbidity benefits of antiplatelet agents in the ACS population. As expected, however, these agents come with an intrinsically increased risk of bleeding which underlies the vast majority of their complications and adverse effects. In today's setting of compounding comorbidities and broadening indications, finding the balance between thrombosis prevention and bleeding risk remains the challenge for all clinicians considering these medications. This article reviews the current main antiplatelet agents that are available for clinical use and outlines their impact on ACS outcome. We also outline factors which affect the response to these agents and discuss strategies to optimize clinical outcomes.
\end{abstract}

Keywords: antiplatelet, acute coronary syndromes, outcomes

\section{Introduction}

Atherosclerosis is a progressive and systemic disease process potentially resulting in grave cardiovascular, neurological, and peripheral vascular complications. Following the spontaneous rupture of an atherosclerotic plaque during an acute coronary syndrome (ACS) or controlled endothelial disruption during percutaneous coronary intervention (PCI), platelets are simultaneously exposed to numerous agonists promoting the process of thrombus formation. The platelet undergoes a morphological change through the process of thrombus formation. Initially, the platelet adheres to the damaged subendothelial matrix via binding of glycoprotein $\mathrm{Ib} / \mathrm{IX}$ to von Willebrand factor. Once adhered to the subcellular matrix, the platelet is activated by collagen via further glycoprotein receptors as well as by thrombin. ${ }^{1}$ Finally, platelet aggregation is initiated by thromboxane $\mathrm{A}_{2}$ and adenosine diphosphate (ADP) with subsequent release of further aggregating factors from the plateletdense granules ${ }^{2}$ resulting in a procoagulant surface required for clot formation. Given their capacity to ablate these above pathways (Figure 1), antiplatelet agents have become the cornerstone of therapy in both ACS and PCI. The potential benefit on patient outcomes is proportional to the degree to which their current antithrombotic potential outweighs the associated current bleeding risk. In this review, we focus on the impact that antiplatelet agents, to date, have had on patient outcomes in ACS. We then address how clinicians and health systems can best utilize these agents to optimize patient outcomes.
Correspondence: Matthew I Worthley Cardiovascular Investigation Unit, Royal Adelaide Hospital, Level 6 Theatre Block, North Terrace, Adelaide, South Australia 5000, Australia

Tel +61882224000

Fax $+6 \mid 882222454$

Email matthew.worthley@adelaide.edu.au 


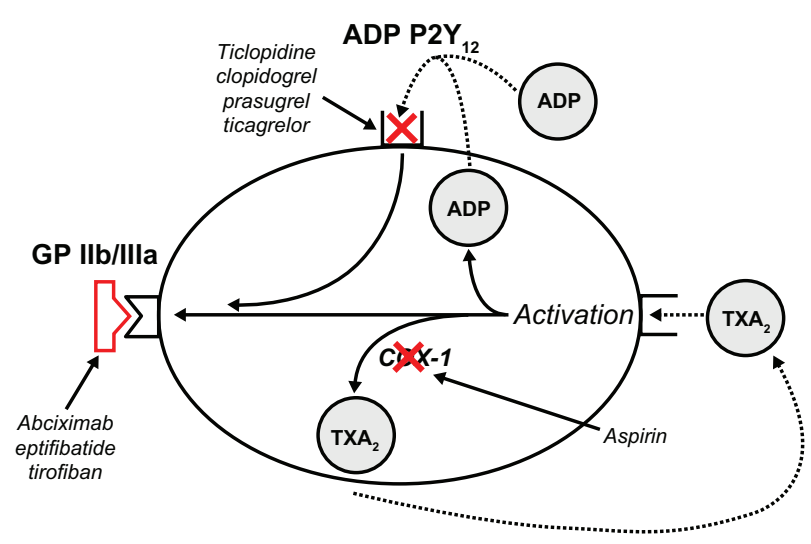

Figure I Mechanism of action of current antiplatelet agents..$^{135}$

\section{Antiplatelet agents Aspirin}

Aspirin has been the mainstay of antithrombotic therapy for many years. When used in doses of 75-300 mg, aspirin irreversibly acetylates serine 530 of cyclooxygenase-1 (COX-1), thereby permanently inhibiting platelet transformation of arachidonic acid (AA) into thromboxane $\mathrm{A}_{2}$, a potent inducer of platelet aggregation. ${ }^{3}$ This $\mathrm{COX}-1$-dependent pathway appears to be dose independent with maximal effect occurring at doses as low as $50 \mathrm{mg}$. Gurbel et al demonstrated a dose response in platelet aggregation in the presence of near-complete (AA) inhibition, suggesting that further antiplatelet effects could occur through COX-1-independent mechanisms. ${ }^{4}$ Furthermore, some of aspirin's benefit may occur downstream from platelet inhibition through mechanisms such as the enhancement of fibrin clot permeability and some weak anti-inflammatory activity and promotion of nitric oxide production in platelets. ${ }^{5}$

Aspirin causes gastrointestinal (GI) side effects in a dosedependent manner. ${ }^{6}$ It is otherwise well tolerated with only a minority of patients experiencing side effects such as asthma $(2 \%-4 \%),{ }^{7}$ rhinitis, urticaria, and angioedema $(0.07 \%-0.2 \%){ }^{8}$ The second International Study of Infarct Survival is the seminal aspirin trial which compared placebo with $160 \mathrm{mg}$ aspirin daily for the treatment of acute myocardial infarction (MI). ${ }^{9}$ For every 1000 patients, 1 month of at least $162 \mathrm{mg}$ aspirin daily prevented 25 deaths and $10-15$ nonfatal MI or strokes. ${ }^{10}$ As aspirin blocks only one of several pathways implicated in platelet activation and aggregation, it is of no surprise that the majority of cardiovascular events are not prevented by aspirin. ${ }^{11}$ To further improve patient outcomes, numerous antiplatelet agents blocking COX-1-independent pathways have been developed over the last three decades leading to further significant reductions in thrombotic events across the cardiovascular disease continuum.

\section{ADP receptor antagonists}

ADP is a platelet activator released from red blood cells, activated platelets, and damaged endothelial cells, which induces platelet adhesion and aggregation..$^{12}$ Adenine nucleotides interact with $\mathrm{P} 2$ receptors, which are distributed in many different cell types including endothelial, smooth muscle, and epithelial cells as well as in platelets. These receptors can be subdivided into the $\mathrm{P} 2 \mathrm{X}$ ligand-gated ion channel and the two P2Y G protein-coupled receptors (P2Y1 and P2Y12) both of which have to be coactivated for normal ADP-induced platelet aggregation to occur. ${ }^{12} \mathrm{~A}$ well-conducted in vitro study has shown that even in conditions of near complete P2Y12 inhibition by thienopyridines, ADP is still capable of inducing platelet conformational change and residual aggregation via the P2Y1 receptor. ${ }^{13}$ The currently available ADP receptor antagonists i) ticlopidine, ii) clopidogrel, iii) prasugrel, and iv) ticagrelor will be discussed in detail.

\section{Ticlopidine}

Ticlopidine was the first commercially available thienopyridinederivative ADP receptor antagonist gaining marketing approval in 1991. Its use increased significantly after numerous trials demonstrated the superiority of the combination of ticlopidine and aspirin in maintaining coronary stent patency following PCI. ${ }^{14,15}$ It is a prodrug that is metabolized in the liver into an active metabolite which irreversibly blocks the P2Y12 ADP receptor for the lifetime of the platelet (7-10 days). Clinically relevant antiplatelet activity at the standard dose $(250 \mathrm{mg}$ twice daily, oral) occurs at $24-48 \mathrm{~h}$, peaking at 3-5 days. The unacceptably high incidence of GI side effects (30\%-50\% vomiting, nausea, and diarrhea) precluded the use of a higher loading dose (500 mg daily, oral). ${ }^{16,17}$ Neutropenia as a side effect of ticlopidine was first noted in phase III trials and was subsequently shown to be as high as $2.4 \% .{ }^{18}$ Furthermore, ticlopidine use was associated with aplastic anemia, thrombotic thrombocytopenic purpura, agranulocytosis, and pancytopenia. These sometimes turned fatal within the first 3 months, with a median recovery time of 15 days upon cessation of agent. ${ }^{19}$ Hence, it is no surprise that ticlopidine was superseded by the second-generation thienopyridine derivative clopidogrel. A meta-analysis comparing the two agents showed that clopidogrel led to a reduction in major adverse cardiac events (MACE) including mortality, with better tolerability and a favorable side effect profile. ${ }^{20}$ At present, use of ticlopidine is limited to cases of clopidogrel intolerance and in settings where the use of the newer antiplatelet agents may not be economically feasible. The use of ticlopidine requires 2-weekly blood counts during the first 3 months of therapy, 
although the optimal frequency and utility of subsequent monitoring are not well defined.

\section{Clopidogrel}

Like its predecessor, clopidogrel is a prodrug that requires hepatic cytochrome P450-dependent biotransformation into an active metabolite, which irreversibly blocks the P2Y12 ADP receptor. It undergoes intestinal absorption which is unaffected by food or antacids. ${ }^{21,22}$ Clopidogrel absorption is controlled by the $A B C B 1$ gene, which exhibits genetic polymorphism and codifies for the intestinal P-glycoprotein multidrug resistance transporter (MDR1). The impact of polymorphism at this locus on overall platelet aggregation and patient outcomes remains controversial with two well-conducted studies showing conflicting results. ${ }^{23,24}$ Once it reaches the bloodstream, 85\% of the parent drug is metabolized into an inactive form. The remaining $15 \%$ is metabolized via a two-step process with the participation of several CYP450 isoenzymes. The CYP2C19 isoenzyme is involved in both steps, and recent studies have shown a strong association between allelic variations at this locus and increased cardiovascular events despite clopidogrel treatment. ${ }^{23-27}$ Not surprisingly, the pharmacodynamic response to clopidogrel shows significant interpatient variability across a normal distribution. ${ }^{28}$ Without the administration of a loading dose, maximal platelet inhibition occurs after 3-5 days at the standard oral daily dose of $75 \mathrm{mg}$. Loading doses of 300 and $600 \mathrm{mg}$ result in maximal inhibition of platelet aggregation (IPA) at 6 and $2 \mathrm{~h}$, respectively. ${ }^{29}$ The minimum dose of clopidogrel required to maintain maximal platelet inhibition in most subjects is $60 \mathrm{mg}$; thus, the standard daily dose of $75 \mathrm{mg}$ exposes patients to incomplete platelet inhibition if compliance is unreliable. ${ }^{30}$

Clopidogrel has been extensively studied in both the non-ST elevation myocardial infarction (NSTEMI) and ST elevation myocardial infarction (STEMI) populations. The CURE study randomized 12,562 patients suffering from NSTE-ACS to receive aspirin and either clopidogrel (300/75 mg) or placebo for an average of 9 months. ${ }^{31}$ Primary outcome (death, MI, or stroke at 12 months) was significantly less in the clopidogrel $\operatorname{arm}(9.3 \%$ vs $11.4 \%$; relative risk $[\mathrm{RR}]=0.8 ; P<0.001)$, although at the expense of increased major $(3.7 \%$ vs $2.7 \%$; $P=0.001)$ and minor bleeding $(5.1 \%$ vs $2.4 \% ; P<0.001)$. A subset of 2658 patients who underwent an invasive strategy was studied in PCI-CURE. ${ }^{32}$ Despite significant crossover, composite endpoints of death, MI, or urgent target vessel revascularization within 30 days were $6.1 \%$ in the control group versus $3.5 \%$ in clopidogrel $\operatorname{arm}(P=0.016)$ with similar bleeding outcomes. COMMIT/CCS-2 ${ }^{33}$ and CLARITY-TIMI $28^{34}$ both confirmed the superiority of dual antiplatelet therapy (DAT) over aspirin monotherapy in STEMI patients.

Rates of clopidogrel-induced neutropenia in the early trials were extremely low varying between $0 \%{ }^{35}$ and $0.12 \% .^{31}$ Thrombotic thrombocytopenic purpura, ${ }^{36}$ suppression in all bone marrow lineages, ${ }^{37}$ and various allergic reactions ${ }^{38,39}$ have all been reported (rate $<0.1 \%$ ) in association with clopidogrel use mostly occurring in the first month of therapy.

\section{Prasugrel}

The third-generation thienopyridine, prasugrel, is a prodrug whose active metabolite R-138727 irreversibly binds to the P2Y12 receptor. Its activation occurs in a two-step process with initial rapid hydrolysis to a thiolactone with a further conversion to its thiol-containing pharmacologically active metabolite R-138727 by oxidation via P450 cytochromes. ${ }^{40}$ Absorption of prasugrel is decreased by factors which increase gastric $\mathrm{pH}$. Coadministration with the proton pump inhibitor (PPI) lansoprazole, however, does not alter prasugrel's efficacy as measured by IPA. ${ }^{41}$ Furthermore, a US Food and Drug Administration (FDA) analysis suggested that antiacid use did not affect prasugrel's clinical efficacy. ${ }^{42}$

The maximal concentration of the active metabolite is seen after 30 min of oral dosing, ${ }^{43}$ with maximal platelet inhibition occurring at $1 \mathrm{~h}$ with a 60-mg loading dose. ${ }^{44}$ Prasugrel was found to be $\sim 10$-fold more potent than clopidogrel in inhibiting thrombus formation and increasing bleeding time. ${ }^{45}$ This pharmacodynamic superiority is most likely a consequence of the more extensive and rapid formation of the equipotent active metabolite. ${ }^{46}$

The TRITON-TIMI 38 compared a 60-mg loading dose of prasugrel followed by $10 \mathrm{mg}$ daily dosing with standard clopidogrel dosing in high-risk ACS patients undergoing PCI. Importantly, randomization only occurred once coronary anatomy was known; hence, the study did not test the two agents as upstream therapy given in the emergency department to ACS patients prior to proceeding to cardiac catheterization. ${ }^{47}$ Prasugrel use resulted in a $19 \%$ relative risk reduction $(9.9 \%$ for prasugrel vs $12.1 \%$ for clopidogrel; hazard ratio $(\mathrm{HR})=0.81 ; P<0.001)$ for the composite primary efficacy endpoint of death from cardiovascular causes, nonfatal MI, or nonfatal stroke. This benefit occurred at the expense of an increase in the rate of noncoronary artery bypass graft $(\mathrm{CABG})$-related major bleeding $(\mathrm{HR}=1.32 ; 95 \%$ confidence interval (CI): 1.03-1.68; number needed to harm $(\mathrm{NNH})=167 ; P=0.03)$ and a significantly higher rate of 
CABG-related bleeding in the prasugrel group $(13.4 \%$ vs $3.2 \%$; NNH $=10$ ). Of note, the majority of the benefit was accrued in the first 3 days, and when adjudicated episodes of MI were removed from the analysis, no further separation of the Kaplan-Meier curves occurred after 30 days. ${ }^{48,49}$ Prasugrel use did not decrease all-cause mortality. A post hoc subgroup analysis by the TRITON authors identified the elderly (age $>75$ years), patients weighing $<60 \mathrm{~kg}$, and those with past history of stroke or transient ischemic attack as having unfavorable bleeding risk-benefit profiles. Currently, the FDA has approved prasugrel use for ACS patients undergoing PCI when coronary anatomy is known and likelihood of undergoing $\mathrm{CABG}$ is low. The clinical efficacy of prasugrel in other patient groups such as medically managed patients with unstable angina/NSTEMI is currently being evaluated in the Targeted Platelet Inhibition to Clarify the Optimal Strategy to Medically Manage Acute Coronary Syndromes trial (NCT00699998; TRILOGY ACS).

\section{Ticagrelor}

Ticagrelor is an orally administered nonthienopyridine, which directly and reversibly inhibits the P2Y12 receptor. ${ }^{50}$ Animal studies have shown that irreversible P2Y12 inhibition with ticagrelor can attenuate ADP-mediated vascular vasoconstriction $^{51}$ and inhibit adenosine uptake by red cells, thereby increasing circulating ADP levels which augment the hyperemic response following arterial occlusion. ${ }^{52} \mathrm{~A}$ loading dose of $180 \mathrm{mg}$ provides similar rates of platelet inhibition within $30 \mathrm{~min}$ that a $600-\mathrm{mg}$ loading dose of clopidogrel provides at 8 h. ${ }^{53}$ Maximal IPA occurs within $2 \mathrm{~h}$ of dosing, with a dose of $100 \mathrm{mg}$ twice daily maintaining near complete IPA and limited added inhibition from increasing doses. The half-life is $\sim 7 \mathrm{~h}$, and there is minimal residual antiplatelet effect $48 \mathrm{~h}$ after last dose. ${ }^{54}$ Dose-related dyspnea is a common adverse event occurring in $10 \%-20 \%$ of patients. ${ }^{54,55}$ Among patients experiencing dyspnea, no changes were noted in any cardiopulmonary function parameters at baseline and up to 6 weeks, ${ }^{56}$ and resulted in discontinuation in about $0.8 \%$ of patients. ${ }^{57}$ The PLATO trial showed that among 13,000 ACS patients managed with an early invasive approach, ticagrelor use resulted in a significant decrease $(12.3 \%$ vs $10.2 \% ; \mathrm{HR}=0.84 ; P=0.0001)$ in the composite endpoint (death from vascular causes, MI, or stroke) at 12 months. What distinguishes ticagrelor from other antiplatelet and antithrombotic agents is that the overall mortality benefit $(4.5 \%$ vs $5.9 \% ; P<0.001)$ was mainly achieved by decreasing rates of MI $(2.8 \%$ vs $2.2 \% ; P=0.03)$ without increasing major non-CABG-related bleeding events using the TRITON Trial definition. ${ }^{58}$ Ticagrelor acts directly in a dose-dependent manner with a rapid onset and offset of its antiplatelet effect. These characteristics make it ideally suited to the acute setting of ACS when coronary anatomy is not known and in cohorts where semielective/urgent surgery necessitates discontinuation of antiplatelet therapy. In July 2010, the FDA Cardiovascular and Renal Advisory Committee voted 7:1 in favor of approving this medication for the indication of a troponin-positive ACS. The time for review, however, has recently been extended as the FDA was uncertain how to evaluate the lack of effect of this drug in the PLATO study in patients enrolled in sites from the USA. ${ }^{59}$

\section{Glycoprotein Ilb/Illa inhibitors}

Glycoprotein IIb/IIIa inhibitors (GPIs) are intravenous agents that inhibit fibrinogen-mediated platelet aggregation and block the expression of the prothrombotic CD40 ligand. ${ }^{60}$ Abciximab, tirofiban, and eptifibatide are the three GPIs currently available for clinical use. At optimal doses, these agents result in prompt, uniform, and very potent IPA when compared to oral antiplatelet agents. ${ }^{16}$ The major risk with their use is increased bleeding episodes, especially in certain at-risk subgroups (diabetics, chronic kidney disease, and elderly) and when inappropriate dosing occurs. ${ }^{61}$ Thrombocytopenia is associated with abciximab and tirofiban use and occurs at a frequency of $2.4 \%$ and $0.5 \%$, respectively. It occurs within the first $24 \mathrm{~h}$ and is associated with adverse outcomes. ${ }^{62}$ GPI use is recommended by the American College of Cardiology (ACC)/American Heart Association (AHA) guidelines in selected patients with NSTEMI/UA, ${ }^{63}$ STEMI, ${ }^{64}$ and those undergoing PCI. ${ }^{65}$ The Harmonizing Outcomes with Revascularization and Stents in Acute Myocardial Infarction trial compared bivalirudin (a direct thrombin inhibitor) alone with heparin plus a GPI in patients with STEMI undergoing primary PCI. Bivalirudin alone led to a significant decrease in overall mortality at 30 days $(2.1 \%$ vs $3.1 \% ; P=0.047$ ). This study has led many to question the clinical utility of GPIs in STEMI patients.

The Early Glycoprotein IIb/IIIa inhibition in NonST-Segment Elevation Acute Coronary Syndrome trial compared routine eptifibatide use with delayed provisional use in NSTEMI in whom an invasive strategy is pursued $(\mathrm{N}=9492)$. Routine use did not affect the primary composite endpoint (death, MI, recurrent ischemia necessitating urgent revascularization, or thrombotic bailout at $96 \mathrm{~h}$ ) and resulted in a higher incidence in bleeding events and transfusions. ${ }^{66}$ The routine use of GPIs in ACS cannot be justified. Selective downstream use in high-risk ACS patients and following complicated PCI is likely to continue. 
A summary of the important clinically used antiplatelet agents is shown in Table 1.

\section{Impact on patient outcomes}

An individual patient is best served by antiplatelet agents if the thrombotic risk significantly outweighs the resultant risk of bleeding. For any particular disease process, this critical balance depends on a myriad of factors including age, patient comorbodities, stage of disease process, pharmacogenetics, and choice of treatment modality. It is through i) maximizing adherence to therapy, ii) evaluating bleeding risk, iii) applying methods to reduce bleeding risk, iv) ensuring pharmacodynamic efficacy, and v) minimizing drug interactions that clinicians can optimize treatment outcomes with antiplatelet agents in ACS.

\section{Adherence}

Adherence can be viewed as a shared process where the care provider and patient work together to ensure that evidencebased treatment is administered during the patient's hospitalization and subsequently taken regularly for the recommended duration of treatment upon discharge. Adherence to ACC/ AHA guidelines during index hospitalization in ACS has been shown in numerous studies to correlate with decreased morbidity and mortality. ${ }^{67}$ An observational study of more than 65,000 patients demonstrated that for every $10 \%$ increase in composite adherence to nine ACC/AHA Class I recommended therapies, a $10 \%$ reduction in in-hospital mortality ensued (adjusted OR $=0.90 ; 95 \%$ CI: $0.84-0.97) .{ }^{68}$ Societal and governmental quality improvement programs,${ }^{69,70}$ registries, ${ }^{71}$ guideline-based tools ${ }^{72}$ and the use of standardized patient pathway medication forms ${ }^{73}$ have all been shown to improve care providers adherence to guidelines.

The transition period from hospital discharge to the outpatient setting is the period where the majority of patientinitiated drug discontinuation occurs. ${ }^{74,75}$ A study by Ho et al found that one in six patients delayed filling in their index clopidogrel script following drug-eluting stent (DES) implantation and subsequently went on to have long gaps between future clopidogrel refills. This group of patients was at increased risk ( $\mathrm{HR}=1.53 ; 95 \% \mathrm{CI}: 1.25-1.87)$ of mortality and future cardiovascular events. ${ }^{76}$ Patient factors known to predict poor adherence to pharmacotherapy following ACS include insurance status, level of education, number of medications, and older age. ${ }^{77}$ The utility and cost-effectiveness requires targeting at-risk patients and patients who delay filling their scripts with intensive education, reminder tools, and more regular follow-up appointments, although intuitive will need to be investigated in randomized trials. A newly identified factor specifically predictive of inappropriate cessation of antiplatelet therapy is that of minor (nuisance) bleeding. Up to $28 \%$ of patients on DAT experience nuisance bleeding, resulting in high cessation rates of one $(5 \%)$ or both $(1 \%)$ antiplatelet agents. ${ }^{78}$ Of note, patients who experience a bleed and receive follow-up care from a cardiologist are more likely to maintain antiplatelet therapy than those who receive follow-up from other health professionals. ${ }^{79}$

Table I Summary of current antiplatelet agents approved for clinical use in the acute coronary syndromes population

\begin{tabular}{|c|c|c|c|c|c|c|}
\hline & Aspirin & Ticlopidine & Clopidogrel & Prasugrel & Ticagrelor & $\begin{array}{l}\text { Abciximab, } \\
\text { tirofiban, } \\
\text { eptifibatide }\end{array}$ \\
\hline Group & Acetylsalicylic acid & Thienopyridine & Thienopyridine & Thienopyridine & $\begin{array}{l}\text { Cyclopentyl- } \\
\text { triazolo-pyridine }\end{array}$ & $\begin{array}{l}\text { GP Ilb/IIla } \\
\text { inhibitors }\end{array}$ \\
\hline FDA approval & 1965 & $199 \mid$ & 1997 & 2009 & $\begin{array}{l}\text { Phase III } \\
\text { complete } 2009\end{array}$ & $1993->$ \\
\hline Route & Oral & Oral & Oral & Oral & Oral & IV \\
\hline Pharmacokinetics & $\begin{array}{l}\text { Block COX } \\
\text { to prevent } \\
\text { formation of } \\
\text { thromboxane } \mathrm{A}_{2} \\
\text { and prostaglandins }\end{array}$ & $\begin{array}{l}\text { Prodrug, modify } \\
\text { P2YI } 2 \text { receptor, } \\
\text { inhibiting } \\
\text { activation of } \\
\text { GP Ilb/IIA complex }\end{array}$ & $\begin{array}{l}\text { Prodrug, modify } \\
\text { P2YI } 2 \text { receptor, } \\
\text { inhibiting } \\
\text { activation of } \\
\text { GP IIb/IIA complex }\end{array}$ & $\begin{array}{l}\text { Prodrug, modify } \\
\text { P2YI } 2 \text { receptor, } \\
\text { inhibiting } \\
\text { activation of } \\
\text { GP Ilb/IIA complex }\end{array}$ & $\begin{array}{l}\text { Direct-acting, } \\
\text { inhibitor of } \mathrm{P} 2 \mathrm{Y} 12\end{array}$ & $\begin{array}{l}\text { Blocks binding } \\
\text { of von Willebrand } \\
\text { factor to GP Ilb/llla, } \\
\text { inhibiting platelet } \\
\text { aggregation }\end{array}$ \\
\hline Inhibition & Irreversible & Irreversible & Irreversible & Irreversible & Reversible & $\begin{array}{l}\text { Abciximab: } \\
\text { irreversible } \\
\text { Others: reversible }\end{array}$ \\
\hline Frequency & Daily & Twice daily & Daily & Daily & Twice daily & Once \\
\hline $\begin{array}{l}\text { Time to peak } \\
\text { effect }\end{array}$ & $\begin{array}{l}20 \mathrm{~min} \\
(150-300-\mathrm{mg} \text { load })\end{array}$ & $\begin{array}{l}\mathrm{I}-3 \mathrm{~h} \\
\text { (250-mg dose) }\end{array}$ & $\begin{array}{l}4-6 \mathrm{~h} \\
\text { (300-mg load) }\end{array}$ & $\begin{array}{l}\text { I h } \\
\text { (60-mg load) }\end{array}$ & $\begin{array}{l}2 \mathrm{~h} \\
\text { (I80-mg load) }\end{array}$ & $10 \mathrm{~min}$ \\
\hline Metabolism & Hepatic & Hepatic & Hepatic & Hepatic & Direct/none & None \\
\hline Clearance & Renal & Renal/biliary & Renal/biliary & Renal & Biliary & Renal \\
\hline
\end{tabular}

Notes: Taken from multiple sources. 
Of concern is that $32 \%$ of cases of inappropriate discontinuation of antiplatelet agents were the result of a health professional's recommendation. ${ }^{76}$ An observational study in a noncardiac preoperative clinic setting showed that following coronary stent implantation, the majority of patients had very poor understanding of the rationale, duration, and risk of discontinuation of antiplatelet therapy. Surgical instructions regarding antiplatelet therapy were provided in 57\% of patients. Alarmingly, however, cardiology input was only documented in $17 \%$ of cases.$^{80}$ For improved outcomes in the perioperative setting, providers of cardiovascular care must ensure adequate patient education and collaboration with other health professionals in the decision-making process of antiplatelet therapy management.

\section{Bleeding risk}

Antiplatelet agents prevent death, MI, and other ischemic events through their antithrombotic properties. This benefit is attenuated by an increase in bleeding risk. In PCI, it is known that with increasing levels of antithrombotic therapy, the antithrombotic beneficial effect eventually plateaus. ${ }^{81,82}$ The risk of bleeding in patients with cardiovascular disease is the result of complex interactions between baseline characteristics, comorbidities, type and stage of disease process, drug combinations, and dosing. The delicate risk/benefit balance of antiplatelet therapy is summarized in Figure 2.

In ACS, bleeding in the acute phase is a strong, stepwise independent predictor of death. ${ }^{83-85}$ This risk is more marked in the acute period (first 30 days), ${ }^{84-87}$ and in some studies, it surpasses the risk of MI. ${ }^{84}$ However, unlike MI, the long-term risk remains significant and persists for up to a year. ${ }^{79-82}$

Two recent scoring systems have been validated to predict early bleeding in ACS. ${ }^{84,88}$ The Can Rapid risk stratification of Unstable angina patients Suppress ADverse outcomes with Early implementation of the ACC/AHA guidelines (CRUSADE) score used the following eight admission variables: female sex, diabetes, vascular disease, heart rate, abnormal systolic blood pressure, congestive heart failure, baseline hematocrit, and creatinine clearance to predict inpatient bleeding in ACS patients. ${ }^{88}$ The risk score proposed by Mehran et al relied on age, sex, creatinine clearance, hematocrit, white cell count, type of ACS presentation, and

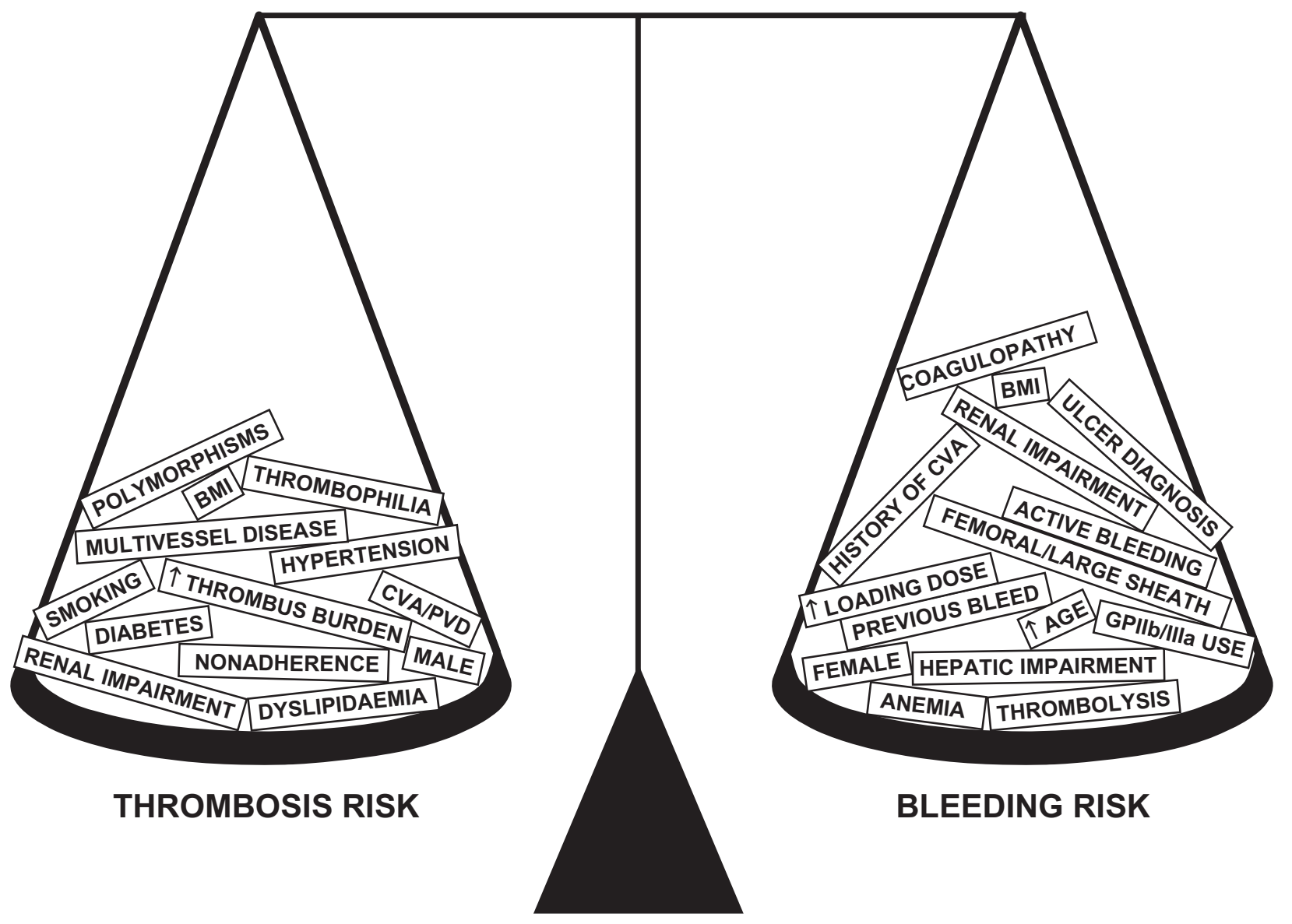

Figure 2 The delicate balance of an individual's comorbidities: risk of thrombosis versus risk of bleeding. Abbreviations: BMI, body mass index; CVA, cerebrovascular accident; PVD, peripheral vascular disease. 
antithrombotic regimen used to predict bleeding within 30 days of presentation. ${ }^{84} \mathrm{~A}$ novel finding from this study was that CABG-related bleeding did not increase mortality, a finding that is likely to generate controversy about the pros and cons of initiating antiplatelet therapy prior to knowing the coronary anatomy. A bleeding obesity paradox has recently been observed where patients with mild (Class I) obesity had the lowest rates of bleeding following PCI after risk adjustment compared to underweight or severely overweight patients. ${ }^{89}$

\section{Interventions to minimize bleeding risk}

Antiplatelet agents increase the risk of gastrointestinal bleeding (GIB): aspirin predominantly by promoting ulcer formation ${ }^{90,91}$ and preventing ulcer healing, ${ }^{92}$ whereas the thienopyridines are believed to promote bleeding at sites of existing lesions caused by nonsteroidal anti-inflammatory drugs (NSAIDs) or infection with Helicobacter pylori. ${ }^{93}$ Ancillary use of other medications such as corticosteroids and anticoagulants further compounds this risk. Of importance, GIB following ACS is independently associated with mortality. ${ }^{94}$ Consensus now exists that upper GI bleeding may be reduced in the setting of antiplatelet use by suppressing gastric acid production and thus promoting the healing of ulcers and erosions as well as potentially stabilizing thrombi. Histamine $\mathrm{H}_{2}$ receptor antagonists, although suppressing acid production by up to $68 \%$, have shown only a modest benefit in patients taking aspirin ${ }^{95}$ and no benefit in those on clopidogrel. ${ }^{96}$ The data for PPIs are far more convincing with one trial showing a $50 \%$ relative risk reduction in patients' baseline risk of GIB (absolute risk 1.2\%) and an absolute risk reduction of $2.8 \%$ per year in patients with $\geq 3$ risk factors for GIB ${ }^{97}$ These findings and other smaller studies ${ }^{98}$ are supported by the most recent trial and largest randomized controlled trial (RCT) which looked at clopidogrel plus omeprazole versus clopidogrel alone. ${ }^{99}$ In the composite outcome of overt or occult bleeding, symptomatic gastroduodenal ulcer, or erosion, a hazard ratio of 0.34 (95\% CI: 0.18-0.63) was observed in the PPI combination arm. An expert consensus document advocates the use of PPI in all patients on DAT and patients with high-risk features. ${ }^{100}$ Patients with a history of peptic ulcer disease should have testing for $H$. pylori and treatment when indicated. A flow diagram summarizing key clinical issues in this area is shown in Figure 3.

A wealth of evidence is accumulating supporting the superior safety of the radial approach for PCI in all groups of ACS patients, particularly regarding bleeding risk. ${ }^{101,102}$ It increases the safety of aggressive platelet inhibition in the acute periprocedural phase and minimizes bleeding

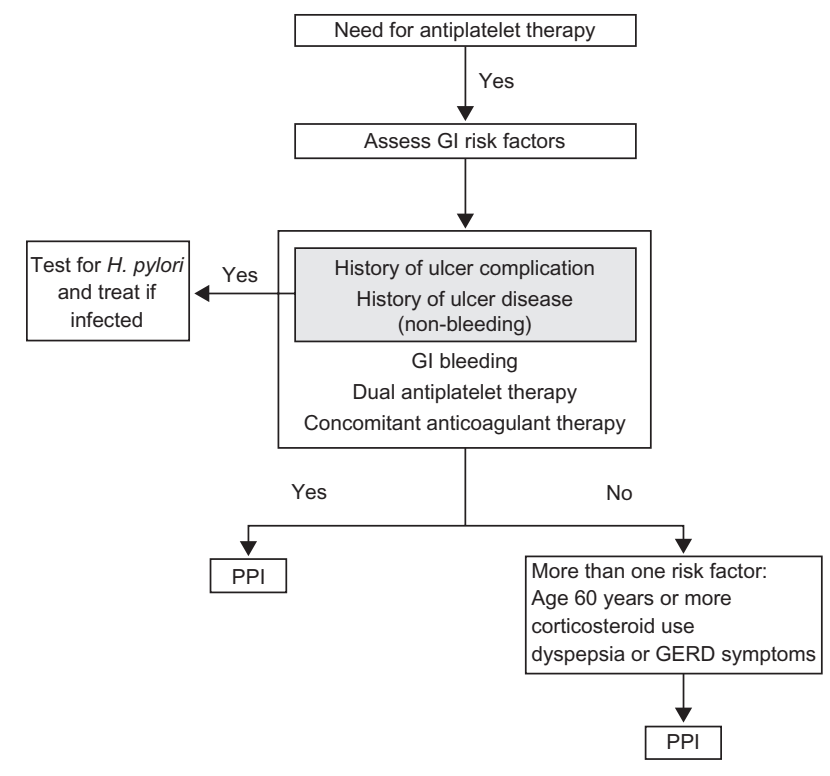

Figure 3 Algorithm proposing an approach to cost effective utilization of PPI cotherapy for the prevention of gastrointestial bleeding.

Copyright (C) 2008, American College of Cardiology. Reproduced with permission from Bhatt DL, Scheiman J, Abraham NS, et al. ACCF/ACG/AHA 2008 expert consensus document on reducing the gastrointestinal risks of antiplatelet therapy and NSAID use: a report of the American College of Cardiology Foundation Task Force on Clinical Expert Consensus Documents. J Am Coll Cardiol. 2008;52(I8):I502-1517. Abbreviations: GERD, gastroesophageal reflux disease; GI, gastrointestinal; PPI, proton pump inhibitor.

and vascular access complications, without significantly increasing procedural time. ${ }^{103-105}$ Nonrandomized evidence now exists for a mortality benefit using radial compared to femoral approach for both stable ${ }^{101}$ and $\mathrm{ACS}^{105}$ patients. We await results of the randomized radial versus femoral access for coronary intervention study due for completion at the end of 2010 for definitive evidence regarding this issue (Clinical Trial: NCT01014273).

An increasing number of patients require long-term anticoagulation with warfarin predominantly for prevention of thromboembolic events in atrial fibrillation. Coexisting indications for concurrent antiplatelet therapy such as ACS and previous PCI are common in this patient population. A recent large, Danish cohort study showed that combining clopidogrel and warfarin carries a bleeding HR of 3.08 (2.323.91) compared with warfarin monotherapy. Additional use of aspirin increases the bleeding HR to $3.70(2.89-4.76) .{ }^{106}$ The bleeding risk, however, is grossly time independent. This concept was supported by an observational Finnish study which highlighted the importance of maintaining DAT in patients on long-term anticoagulation therapy in the first 4 weeks following PCI. ${ }^{107}$ Strategies to minimize the bleeding risk in this patient population include maintaining the international normalized ratio levels at the lowest possible therapeutic level ${ }^{108,109}$ and minimizing the duration of triple therapy with 
the preferential use of bare metal stents (BMS). ${ }^{110}$ The use of a PPI (which will be expanded on later in this article) appears appropriate for moderate to high bleeding risk subjects that require both concomitant anticoagulation and antiplatelet therapy.

The risk of stent thrombosis in patients who undergo PCI and stent implantation decreases exponentially over time. Rates of endothelialization differ between BMS and DESs, influencing the decision about the duration of DAT. This has recently been a major concern with an increase of stent thrombosis rates seen in DES compared to BMS with an associated suggestion of increased adverse outcomes. ${ }^{11}$ This has resulted in many interventional cardiologists electing to prolong DAT in subjects following DES compared to BMS insertion. Definitive studies in this area to guide the clinician are limited; however, recent data suggest that if a patient has been clinically stable on DAT for 12 months following a DES insertion, continuation of DAT for a further 12 months compared to aspirin therapy alone is not associated with any reduction in adverse cardiovascular events. ${ }^{112}$

\section{Pharmacogenetics and pharmacodynamics}

Consistent and effective levels of platelet inhibition are essential for obtaining optimal patient outcomes with antiplatelet therapy in ACS patients. The complex and dynamic nature of platelet function ${ }^{113}$ and the variety of targets for platelet inhibition are some of the reasons why no single platelet function test (PFT) is currently in routine clinical use. ${ }^{114}$ In a recent trial looking at six different PFTs in PCI, only three out of six tests had a modest predictive value for adverse cardiovascular events, and no test predicted bleeding complications. ${ }^{115}$ The intrinsically constant nature of interindividual allelic variation have led some to propose genetic testing as the new standard of care for individualized antiplatelet therapy. ${ }^{116}$

Aspirin resistance has been used to describe incomplete platelet response, with prevalence estimates between $5 \%$ and $65 \% .{ }^{30}$ Lack of a 'gold standard definition', assay variability, and the contribution of composite processes may explain this wide range. ${ }^{117}$ Two meta-analyses using studies with heterogeneous methods have suggested a nearly four-fold increase in recurrent cardiovascular events in patients poorly responsive to aspirin. ${ }^{118,119}$ The clinical utility of point of care assays for aspirin response in ACS should be tested in large randomized trials.

A large body of data supports the association of genetic polymorphisms in the hepatic cytochrome 2C19 (CYP2C19) with variable levels of the active metabolite of clopidogrel. This was subsequently shown to result in high levels of residual platelet reactivity and adverse clinical outcomes, ${ }^{52,66,67,71}$ prompting the FDA to issue a boxed warning about the diminished effectiveness in patients with loss-of-function alleles. ${ }^{120}$ Other factors, both genetic and nongenetic, most likely contribute to this clinically important phenomenon. Response to the newer P2Y12 receptor antagonists (prasugrel, ticagrelor) does not appear to be influenced by CYP2C19 allelic variation. ${ }^{53,121,122}$ The future of individualized antiplatelet therapy may involve a combination of genotypic and phenotypic testing, which will assist in guiding treatment algorithms. While the mechanisms relating to clopidogrel resistance (nonresponders) are multifactorial, the definitive treatment to counteract the associated adverse outcomes remains uncertain. ${ }^{123}$

\section{Drug interactions}

NSAIDs are used daily by more than 30 million people worldwide. ${ }^{124}$ Their use is particularly prevalent amongst the elderly; a group also at increased risk of cardiovascular disease. Ibuprofen, the most widely used NSAID, is believed to interfere with aspirin by binding to COX-1 and attenuating its antiplatelet activity. ${ }^{125}$ This effect has also been observed with other NSAIDs, ${ }^{126-128}$ but specifically not with COX-2 selective inhibitors. ${ }^{129}$ The FDA recommends that aspirin should be taken at least $30 \mathrm{~min}$ before or $8 \mathrm{~h}$ after nonselective NSAID ingestion to preserve its efficacy. ${ }^{130} \mathrm{It}$ is incumbent amongst all providers of care for ACS patients to realize that the use of all nonaspirin NSAIDs is associated with adverse cardiovascular outcomes. ${ }^{131}$ At-risk patients, particularly in the post-ACS and PCI setting, should be provided with education about the risks of NSAIDs (especially over the counter use), and alternative modes of analgesia should be provided wherever possible. ${ }^{132}$

Given their broad indications and frequent coprescription, the purported interaction between PPIs and clopidogrel has generated unprecedented attention in both the lay and research community. Concomitant use of PPIs may competitively inhibit activation of clopidogrel by CYP2C19, thereby reducing its antiplatelet activity in the same way allelic variations have been reported. ${ }^{133}$ The evidence supporting this theory, however, has been conflicting and can be categorized into studies looking at pharmacodynamic and platelet function studies and those looking at clinical effect. In one study of patients who were given a high maintenance dose of clopidogrel, both omeprazole and pantoprazole were associated with reduced platelet inhibition as assessed by vasodilator-stimulated phosphoroprotein 
( $44 \%$ vs $23 \% ; P=0.04$ ). Two other randomized trials utilizing ex vivo assays demonstrated the same attenuation with omeprazole; $;^{77,78}$ however, other PPIs did not seem to have the same impact in two further studies. ${ }^{78,80}$ In terms of clinical effect of interaction, large observational studies of differing size, populations, and methodologies have looked at whether patients prescribed a PPI have had increased CV events, with some reporting small but significant associations yet others reporting no difference. Whether the differences in results reflect a number of confounding factors or true clinical interaction is impossible to determine retrospectively. One of the largest observational studies randomized 13,608 patients to clopidogrel or prasugrel and found no difference between $\mathrm{CV}$ events in those patients on PPI compared to those who were not (regardless of which PPI was used) in either treatment arm (clopidogrel HR $=0.94 ; 95 \%$ CI: $0.80-1.11$ and prasugrel HR $=1.00,95 \%$ CI: $0.84-1.20) .{ }^{79}$ The only RCT published to date, as alluded to above, involved 3761 patients who were randomized to clopidogrel and omeprazole combination or clopidogrel alone. ${ }^{100}$ All patients were also on aspirin, and no difference in composite $\mathrm{CV}$ event rate was observed between the arms (MI, stroke, CABG, and PCI CV death). The conclusions of the study, which appear to refute any potential interaction, have been somewhat controversial given the trial was stopped before full enrollment and the low event rate resulting in broad confidence intervals.

In summary, despite being theoretically plausible and biologically measurable with platelet function testing, the clinical effect of a PPI-clopidogrel interaction is inconsistently demonstrated, of small magnitude when observed, and the only randomized trial refutes its existence. In spite of this and a recent consensus document from the ACC/AHA/AGA which reports an inability to exclude an interaction on current evidence, the FDA remains reticent to remove its black box warning on clopidogrel and has reissued its warning. ${ }^{134}$ The risk of GIB remains an important clinical problem for patients requiring DAT. The consensus statement suggests that the risk reduction with PPIs is substantial in patients with risk factors for GIB (prior bleed, advancing age, concomitant anticoagulation/steroid/NSAID, or H. pylori infection) and thus will outweigh any potential reduction in the $\mathrm{CV}$ efficacy of antiplatelet treatment because of a drug-drug interaction. In patients without GIB risk factors, there appears to be little incremental absolute benefit in adding PPI.

\section{Discussion}

The growing body of evidence highlighting the central role of platelets to the development of ACS ensures that antiplatelet therapy will continue to be the cornerstone of management for the foreseeable future. The relentless search for increasingly aggressive antithrombotic activity has resulted in increased efficacy, but it has come at the expense of increased rates of bleeding. While the quest continues, the current absence of a one-size-fits-all antiplatelet 'panacea' mandates an individualized approach to therapy. Evidence-based algorithms will incorporate evolving trial data assessing duration, timing, and dose of the current agents as well as the impact of new agents on thrombosis and bleeding balance. The not-so-distant future of antiplatelet therapy is destined to account for clinical phenotypes and utilize pharmacogenomics in combination with platelet function testing to individualize therapy. Regular medication reviews and education to both patients and other health care professionals will be critical in ensuring the optimal implementation and utilization of such algorithms.

\section{Disclosure}

None of the authors have conflicts of interest to declare in relation to this paper.

\section{References}

1. Clemetson KJ, Clemetson JM. Platelet collagen receptors. Thromb Haemost. 2001;86(1):189-197.

2. Kamath S, Blann AD, Lip GY. Platelet activation: assessment and quantification. Eur Heart J. 2001;22(17):1561-1571.

3. Patrono C, García-Rodríguez LA, Landolfi R, Baigent C. Low-dose aspirin for the prevention of atherothrombosis. N Engl J Med. 2005; 353(22):2373-2383.

4. Gurbel PA, Bliden KP, DiChiara J, et al. Evaluation of dose-related effects of aspirin on platelet function: results from the AspirinInduced Platelet Effect (ASPECT) study. Circulation. 2007;115(25): 3156-3164.

5. Gurbel PA, Tantry US. Combination antithrombotic therapies. Circulation. 2010;121(4):569-583.

6. Patrono C, Coller B, FitzGerald GA, Hirsh J, Roth G. Platelet-active drugs: the relationships among dose, effectiveness, and side effects: the Seventh ACCP Conference on Antithrombotic and Thrombolytic Therapy. Chest. 2004;126(3 Suppl):234S-264S.

7. Jenkins C, Costello J, Hodge L. Systematic review of prevalence of aspirin induced asthma and its implications for clinical practice. $B M J$. 2004;328(7437):434.

8. Grattan CE. Aspirin sensitivity and urticaria. Clin Exp Dermatol. 2003; 28(2):123-127.

9. Randomised trial of intravenous streptokinase, oral aspirin, both, or neither among 17,187 cases of suspected acute myocardial infarction: ISIS-2. ISIS-2 (Second International Study of Infarct Survival) Collaborative Group. Lancet. 1988;2(8607):349-360.

10. Antithrombotic Trialists' Collaboration. Collaborative meta-analysis of randomised trials of antiplatelet therapy for prevention of death, myocardial infarction, and stroke in high risk patients. BMJ. 2002; 324(7329):71-86.

11. Antiplatelet Trialists' Collaboration. Collaborative overview of randomised trials of antiplatelet therapy - I: prevention of death, myocardial infarction, and stroke by prolonged antiplatelet therapy in various categories of patients. BMJ. 1994;308(6921):81-106.

12. Benoit P, Dogné JM. Platelet ADP receptors and their antagonists. Mini Rev Med Chem. 2003;3(2):145-148. 
13. Hollopeter G, Jantzen HM, Vincent D, et al. Identification of the platelet ADP receptor targeted by antithrombotic drugs. Nature. 2001; 409(6817):202-207.

14. Leon MB, Baim DS, Popma JJ, et al. A clinical trial comparing three antithrombotic-drug regimens after coronary-artery stenting. Stent Anticoagulation Restenosis Study Investigators. N Engl J Med. 1998; 339(23):1665-1671.

15. Schömig A, Neumann FJ, Kastrati A, et al. A randomized comparison of antiplatelet and anticoagulant therapy after the placement of coronaryartery stents. N Engl J Med. 1996;334(17):1084-1089.

16. Gurbel PA, Tantry US. Delivery of glycoprotein IIb/IIIa inhibitor therapy for percutaneous coronary intervention: why not take the intracoronary highway? Circulation. 2010;121(6):739-741.

17. Levine GN, Berger PB, Cohen DJ, et al. Newer pharmacotherapy in patients undergoing percutaneous coronary interventions: a guide for pharmacists and other health care professionals. Pharmacotherapy. 2006;26(11):1537-1556.

18. Sharis PJ, Cannon CP, Loscalzo J. The antiplatelet effects of ticlopidine and clopidogrel. Ann Intern Med. 1998;129(5):394-405.

19. Paradiso-Hardy FL, Angelo CM, Lanctôt KL, Cohen EA. Hematologic dyscrasia associated with ticlopidine therapy: evidence for causality. CMAJ. 2000;163(11):1441-1448.

20. Bhatt DL, Bertrand ME, Berger PB, et al. Meta-analysis of randomized and registry comparisons of ticlopidine with clopidogrel after stenting. J Am Coll Cardiol. 2002;39(1):9-14.

21. Small DS, Farid NA, Li YG, et al. Effect of ranitidine on the pharmacokinetics and pharmacodynamics of prasugrel and clopidogrel. Curr Med Res Opin. 2008;24(8):2251-2257.

22. Quinn MJ, Fitzgerald DJ. Ticlopidine and clopidogrel. Circulation. 1999;100(15):1667-1672.

23. Simon T, Verstuyft C, Mary-Krause M, et al. Genetic determinants of response to clopidogrel and cardiovascular events. $N$ Engl J Med. 2009;360(4):363-375.

24. Shuldiner AR, O'Connell JR, Bliden KP, et al. Association of cytochrome P450 2C19 genotype with the antiplatelet effect and clinical efficacy of clopidogrel therapy. JAMA. 2009;302(8):849-857.

25. Giusti B, Gori AM, Marcucci R, et al. Relation of cytochrome P450 2C19 loss-of-function polymorphism to occurrence of drug-eluting coronary stent thrombosis. Am J Cardiol. 2009;103(6):806-811.

26. Mega JL, Close SL, Wiviott SD, et al. Cytochrome p-450 polymorphisms and response to clopidogrel. $N$ Engl J Med. 2009;360(4): $354-362$.

27. Sibbing D, Stegherr J, Latz W, et al. Cytochrome P450 2C19 loss-offunction polymorphism and stent thrombosis following percutaneous coronary intervention. Eur Heart J. 2009;30(8):916-922.

28. Gurbel PA, Bliden KP, Hiatt BL, O'Connor CM. Clopidogrel for coronary stenting: response variability, drug resistance, and the effect of pretreatment platelet reactivity. Circulation. 2003;107(23): 2908-2913.

29. Hochholzer W, Trenk D, Frundi D, et al. Time dependence of platelet inhibition after a 600-mg loading dose of clopidogrel in a large, unselected cohort of candidates for percutaneous coronary intervention. Circulation. 2005;111(20):2560-2564.

30. Maree AO, Fitzgerald DJ. Variable platelet response to aspirin and clopidogrel in atherothrombotic disease. Circulation. 2007;115(16): 2196-2207.

31. Yusuf S, Zhao F, Mehta SR, Chrolavicius S, Tognoni G, Fox KK. Effects of clopidogrel in addition to aspirin in patients with acute coronary syndromes without ST-segment elevation. N Engl J Med. 2001;345(7) :494-502.

32. Mehta SR, Yusuf S, Peters RJ, et al. Effects of pretreatment with clopidogrel and aspirin followed by long-term therapy in patients undergoing percutaneous coronary intervention: the PCI-CURE study. Lancet. 2001;358(9281):527-533.

33. Chen ZM, Jiang LX, Chen YP, et al. Addition of clopidogrel to aspirin in 45,852 patients with acute myocardial infarction: randomised placebocontrolled trial. Lancet. 2005;366(9497):1607-1621.
34. Sabatine MS, Cannon CP, Gibson CM, et al. Addition of clopidogrel to aspirin and fibrinolytic therapy for myocardial infarction with STsegment elevation. $N$ Engl J Med. 2005;352(12):1179-1189.

35. Bertrand ME, Rupprecht HJ, Urban P, Gershlick AH. Double-blind study of the safety of clopidogrel with and without a loading dose in combination with aspirin compared with ticlopidine in combination with aspirin after coronary stenting: the clopidogrel aspirin stent international cooperative study (CLASSICS). Circulation. 2000;102(6): 624-629.

36. Bennett CL, Connors JM, Carwile JM, et al. Thrombotic thrombocytopenic purpura associated with clopidogrel. N Engl J Med. 2000; 342(24):1773-1777.

37. Almsherqi ZA, McLachlan CS, Sharef SM. Non-bleeding side effects of clopidogrel: have large multi-center clinical trials underestimated their incidence? Int J Cardiol. 2007;117(3):415-417.

38. Fischer TC, Worm M, Groneberg DA. Clopidogrel-associated angioedema. Am J Med. 2003;114(1):77-78.

39. Khambekar SK, Kovac J, Gershlick AH. Clopidogrel induced urticarial rash in a patient with left main stem percutaneous coronary intervention: management issues. Heart. 2004;90(3):e14.

40. Hagihara K, Kazui M, Kurihara A, et al. Biotransformation of prasugrel, a novel thienopyridine antiplatelet agent, to the pharmacologically active metabolite. Drug Metab Dispos. 2010;38(6):898-904.

41. Small DS, Farid NA, Payne CD, et al. Effects of the proton pump inhibitor lansoprazole on the pharmacokinetics and pharmacodynamics of prasugrel and clopidogrel. J Clin Pharmacol. 2008;48(4): 475-484.

42. US Food and Drug Administration. Cardiovascular and Renal Drug Advisory Committee Briefing Document on Prasugrel for ACS. Rockville (MD): FDA; 2009. Available from: http://www.fda.gov/ohrms/ dockets/ac/09/briefing/2009-4412b1-01-FDA.pdf. Accessed 2010 May 22.

43. Jakubowski JA, Winters KJ, Naganuma H, Wallentin L. Prasugrel: a novel thienopyridine antiplatelet agent. A review of preclinical and clinical studies and the mechanistic basis for its distinct antiplatelet profile. Cardiovasc Drug Rev. 2007;25(4):357-374.

44. Wiviott SD, Trenk D, Frelinger AL, et al. Prasugrel compared with high loading- and maintenance-dose clopidogrel in patients with planned percutaneous coronary intervention: the prasugrel in comparison to clopidogrel for inhibition of platelet activation and aggregation-thrombolysis in myocardial infarction 44 trial. Circulation. 2007;116(25):2923-2932.

45. Matsushima N, Jakubowski JA, Asai F, et al. Platelet inhibitory activity and pharmacokinetics of prasugrel (CS-747) a novel thienopyridine P2Y12 inhibitor: a multiple-dose study in healthy humans. Platelets. 2006;17(4):218-226.

46. Norgard NB, Abu-Fadel M. Comparison of prasugrel and clopidogrel in patients with acute coronary syndrome undergoing percutaneous coronary intervention. Vasc Health Risk Manag. 2009;5: 873-882.

47. Wiviott SD, Braunwald E, McCabe $\mathrm{CH}$, et al. Prasugrel versus clopidogrel in patients with acute coronary syndromes. N Engl J Med. 2007; 357(20):2001-2015.

48. Serebruany VL. The FDA prasugrel review: adjudication of myocardial infarction controversy. Cardiology. 2009;114(2):126-129.

49. Serebruany VL. Bleeding risks with prasugrel in the TRITON trial: good news ... bad news. Cardiology. 2008;111(4):265-267.

50. Angiolillo DJ, Guzman LA. Clinical overview of promising nonthienopyridine antiplatelet agents. Am Heart J. 2008;156(2 Suppl): S23-S28.

51. Wang K, Zhou X, Zhou Z, et al. Blockade of the platelet P2Y12 receptor by AR-C69931MX sustains coronary artery recanalization and improves the myocardial tissue perfusion in a canine thrombosis model. Arterioscler Thromb Vasc Biol. 2003;23(2):357-362.

52. Husted S, van Giezen JJ. Ticagrelor: the first reversibly binding oral P2Y12 receptor antagonist. Cardiovasc Ther. 2009;27(4): 259-274. 
53. Gurbel PA, Bliden KP, Butler K, et al. Randomized double-blind assessment of the ONSET and OFFSET of the antiplatelet effects of ticagrelor versus clopidogrel in patients with stable coronary artery disease: the ONSET/OFFSET study. Circulation. 2009;120(25): 2577-2585.

54. Husted S, Emanuelsson H, Heptinstall S, Sandset PM, Wickens M, Peters G. Pharmacodynamics, pharmacokinetics, and safety of the oral reversible P2Y12 antagonist AZD6140 with aspirin in patients with atherosclerosis: a double-blind comparison to clopidogrel with aspirin. Eur Heart J. 2006;27(9):1038-1047.

55. Cannon CP, Husted S, Harrington RA, et al. Safety, tolerability, and initial efficacy of AZD6140, the first reversible oral adenosine diphosphate receptor antagonist, compared with clopidogrel, in patients with non-ST-segment elevation acute coronary syndrome: primary results of the DISPERSE-2 trial. J Am Coll Cardiol. 2007;50(19): $1844-1851$.

56. Storey RF, Bliden KP, Patil SB, et al. Incidence of dyspnea and assessment of cardiac and pulmonary function in patients with stable coronary artery disease receiving ticagrelor, clopidogrel, or placebo in the ONSET/OFFSET study. $J$ Am Coll Cardiol. 2010;56(3): 185-193.

57. Cannon CP, Harrington RA, James S, et al. Comparison of ticagrelor with clopidogrel in patients with a planned invasive strategy for acute coronary syndromes (PLATO): a randomised double-blind study. Lancet. 2010;375(9711):283-293.

58. Stone GW. Ticagrelor in ACS: redefining a new standard of care? Lancet. 2010;375(9711):263-265.

59. Hughes S. First "comparison" of prasugrel and ticagrelor. 2010 Sep16. Available from: http://www.theheart.org/article/1122713.do. Accessed 2010 Oct 20.

60. Chandler AB, Earhart AD, Speich HE, et al. Regulation of CD40L (CD154) and CD62P (p-selectin) surface expression upon GPIIb-IIIa blockade of platelets from stable coronary artery disease patients. Thromb Res. 2010;125(1):44-52.

61. Alexander KP, Chen AY, Roe MT, et al. Excess dosing of antiplatelet and antithrombin agents in the treatment of non-ST-segment elevation acute coronary syndromes. JAMA. 2005;294(24):3108-3116.

62. Merlini PA, Rossi M, Menozzi A, et al. Thrombocytopenia caused by abciximab or tirofiban and its association with clinical outcome in patients undergoing coronary stenting. Circulation. 2004;109(18): 2203-2206.

63. Anderson JL, Adams CD, Antman EM, et al. ACC/AHA 2007 guidelines for the management of patients with unstable angina/non-STelevation myocardial infarction: a report of the American College of Cardiology/American Heart Association Task Force on practice guidelines (writing committee to revise the 2002 guidelines for the management of patients with unstable angina/non-ST-elevation myocardial infarction) developed in collaboration with the American College of Emergency Physicians, the Society for Cardiovascular Angiography and Interventions, and the Society of Thoracic Surgeons endorsed by the American Association of Cardiovascular and Pulmonary Rehabilitation and the Society for Academic Emergency Medicine. J Am Coll Cardiol. 2007;50(7):e1-e157.

64. Antman EM, Hand M, Armstrong PW, et al. 2007 focused update of the ACC/AHA 2004 guidelines for the management of patients with ST-elevation myocardial infarction: a report of the American College of Cardiology/American Heart Association Task Force on practice guidelines. J Am Coll Cardiol. 2008;51(2):210-247.

65. Smith SC Jr, Feldman TE, Hirshfeld JW Jr, et al. ACC/AHA/SCAI 2005 guideline update for percutaneous coronary intervention-summary article: a report of the American College of Cardiology/American Heart Association Task Force on practice guidelines (ACC/AHA/SCAI writing committee to update the 2001 guidelines for percutaneous coronary intervention). J Am Coll Cardiol. 2006;47(1):216-235.

66. Giugliano RP, White JA, Bode C, et al. Early versus delayed, provisional eptifibatide in acute coronary syndromes. N Engl J Med. 2009; 360(21):2176-2190.
67. Eagle KA, Montoye CK, Riba AL, et al. Guideline-based standardized care is associated with substantially lower mortality in medicare patients with acute myocardial infarction: the American College of Cardiology's Guidelines Applied in Practice (GAP) Projects in Michigan. J Am Coll Cardiol. 2005;46(7):1242-1248.

68. Peterson ED, Roe MT, Mulgund J, et al. Association between hospital process performance and outcomes among patients with acute coronary syndromes. JAMA. 2006;295(16):1912-1920.

69. LaBresh KA, Ellrodt AG, Gliklich R, Liljestrand J, Peto R. Get with the guidelines for cardiovascular secondary prevention: pilot results. Arch Intern Med. 2004;164(2):203-209.

70. Mehta RH, Montoye CK, Gallogly M, et al. Improving quality of care for acute myocardial infarction: the Guidelines Applied in Practice (GAP) initiative. JAMA. 2002;287(10):1269-1276.

71. Mehta RH, Roe MT, Chen AY, et al. Recent trends in the care of patients with non-ST-segment elevation acute coronary syndromes: insights from the CRUSADE initiative. Arch Intern Med. 2006;166(18): 2027-2034

72. Mehta RH, Montoye CK, Faul J, et al. Enhancing quality of care for acute myocardial infarction: shifting the focus of improvement from key indicators to process of care and tool use: the American College of Cardiology Acute Myocardial Infarction Guidelines Applied in Practice Project in Michigan: Flint and Saginaw Expansion. J Am Coll Cardiol. 2004;43(12):2166-2173.

73. Bahit MC, Murphy SA, Gibson CM, Cannon CP. Critical pathway for acute ST-segment elevation myocardial infarction: estimating its potential impact in the TIMI 9 registry. Crit Pathw Cardiol. 2002;1(2): 107-112.

74. Coleman EA, Smith JD, Raha D, Min SJ. Posthospital medication discrepancies: prevalence and contributing factors. Arch Intern Med. 2005;165(16):1842-1847.

75. Ho PM, Spertus JA, Masoudi FA, et al. Impact of medication therapy discontinuation on mortality after myocardial infarction. Arch Intern Med. 2006;166(17):1842-1847.

76. Ho PM, Tsai TT, Maddox TM, et al. Delays in filling clopidogrel prescription after hospital discharge and adverse outcomes after drugeluting stent implantation: implications for transitions of care. Circ Cardiovasc Qual Outcomes. 2010;3(3):261-266.

77. Melloni C, Alexander KP, Ou FS, et al. Predictors of early discontinuation of evidence-based medicine after acute coronary syndrome. $\mathrm{Am}$ J Cardiol. 2009;104(2):175-181.

78. Ben-Dor I, Torguson R, Scheinowitz M, et al. Incidence, correlates, and clinical impact of nuisance bleeding after antiplatelet therapy for patients with drug-eluting stents. Am Heart J. 2010;159(5):871-875.

79. Wang TY, Xiao L, Alexander KP, et al. Antiplatelet therapy use after discharge among acute myocardial infarction patients with in-hospital bleeding. Circulation. 2008;118(21):2139-2145.

80. Trentman TL, Rosenfeld DM, Danielson DR, Hagstrom SG. Drug-eluting stents: patient understanding of the risks of premature cessation of antiplatelet drugs. J Cardiothorac Vasc Anesth. 2008; 22(6):806-810.

81. Chew DP, Bhatt DL, Lincoff AM, et al. Defining the optimal activated clotting time during percutaneous coronary intervention: aggregate results from 6 randomized, controlled trials. Circulation. 2001;103(7): 961-966.

82. Brener SJ, Moliterno DJ, Lincoff AM, Steinhubl SR, Wolski KE, Topol EJ. Relationship between activated clotting time and ischemic or hemorrhagic complications: analysis of 4 recent randomized clinical trials of percutaneous coronary intervention. Circulation. 2004; 110(8):994-998

83. Ndrepepa G, Berger PB, Mehilli J, et al. Periprocedural bleeding and 1-year outcome after percutaneous coronary interventions: appropriateness of including bleeding as a component of a quadruple end point. J Am Coll Cardiol. 2008;51(7):690-697.

84. Mehran R, Pocock SJ, Nikolsky E, et al. A risk score to predict bleeding in patients with acute coronary syndromes. $J$ Am Coll Cardiol. 2010; 55(23):2556-2566. 
85. Kinnaird TD, Stabile E, Mintz GS, et al. Incidence, predictors, and prognostic implications of bleeding and blood transfusion following percutaneous coronary interventions. Am J Cardiol. 2003; 92(8):930-935.

86. Moscucci M, Fox KA, Cannon CP, et al. Predictors of major bleeding in acute coronary syndromes: the Global Registry of Acute Coronary Events (GRACE). Eur Heart J. 2003;24(20):1815-1823.

87. Rao SV, O'Grady K, Pieper KS, et al. Impact of bleeding severity on clinical outcomes among patients with acute coronary syndromes. Am J Cardiol. 2005;96(9):1200-1206.

88. Subherwal S, Bach RG, Chen AY, et al. Baseline risk of major bleeding in non-ST-segment-elevation myocardial infarction: the CRUSADE (Can Rapid risk stratification of Unstable angina patients Suppress ADverse outcomes with Early implementation of the ACC/AHA Guidelines) bleeding score. Circulation. 2009;119(14):1873-1882.

89. Delhaye C, Wakabayashi K, Maluenda G, et al. Body mass index and bleeding complications after percutaneous coronary intervention: does bivalirudin make a difference? Am Heart J. 2010; 159(6):1139-1146.

90. Scheiman JM. NSAIDs, gastrointestinal injury, and cytoprotection. Gastroenterol Clin North Am. 1996;25(2):279-298.

91. Lanas A, Scheiman J. Low-dose aspirin and upper gastrointestinal damage: epidemiology, prevention and treatment. Curr Med Res Opin. 2007;23(1):163-173.

92. Ma L, Elliott SN, Cirino G, Buret A, Ignarro LJ, Wallace JL. Platelets modulate gastric ulcer healing: role of endostatin and vascular endothelial growth factor release. Proc Natl Acad Sci U S A. 2001; 98(11):6470-6475.

93. Abraham NS, Graham DY. NSAIDs and gastrointestinal complications: new clinical challenges. Expert Opin Pharmacother. 2005; 6(15):2681-2689.

94. Nikolsky E, Stone GW, Kirtane AJ, et al. Gastrointestinal bleeding in patients with acute coronary syndromes: incidence, predictors, and clinical implications: analysis from the ACUITY (Acute Catheterization and Urgent Intervention Triage Strategy) trial. J Am Coll Cardiol. 2009;54(14):1293-1302.

95. Taha AS, McCloskey C, Prasad R, Bezlyak V. Famotidine for the prevention of peptic ulcers and oesophagitis in patients taking low-dose aspirin (FAMOUS): a phase III, randomised, double-blind, placebocontrolled trial. Lancet. 2009;374(9684):119-125.

96. Lanas A, García-Rodríguez LA, Arroyo MT, et al. Effect of antisecretory drugs and nitrates on the risk of ulcer bleeding associated with nonsteroidal anti-inflammatory drugs, antiplatelet agents, and anticoagulants. Am J Gastroenterol. 2007;102(3):507-515.

97. Ray WA, Murray KT, Griffin MR, et al. Outcomes with concurrent use of clopidogrel and proton-pump inhibitors: a cohort study. Ann Intern Med. 2010;152(6):337-345.

98. Ng FH, Wong SY, Lam KF, et al. Gastrointestinal bleeding in patients receiving a combination of aspirin, clopidogrel, and enoxaparin in acute coronary syndrome. Am J Gastroenterol. 2008;103(4):865-871.

99. Bhatt DL, Cryer BL, Contant CF, et al. Clopidogrel with or without Omeprazole in Coronary Artery Disease. N Engl J Med. 2010; 363(20):1909-1917.

100. Bhatt DL, Scheiman J, Abraham NS, et al. ACCF/ACG/AHA 2008 expert consensus document on reducing the gastrointestinal risks of antiplatelet therapy and NSAID use: a report of the American College of Cardiology Foundation Task Force on Clinical Expert Consensus Documents. J Am Coll Cardiol. 2008;52(18):1502-1517.

101. Chase AJ, Fretz EB, Warburton WP, et al. Association of the arterial access site at angioplasty with transfusion and mortality: the M.O.R.T.A.L study (Mortality benefit Of Reduced Transfusion after percutaneous coronary intervention via the Arm or Leg). Heart. 2008; 94(8):1019-1025.

102. Vorobcsuk A, Kónyi A, Aradi D, et al. Transradial versus transfemoral percutaneous coronary intervention in acute myocardial infarction systematic overview and meta-analysis. Am Heart J. 2009; 158(5):814-821.
103. Bertrand OF, Larose E, Rodés-Cabau J, et al. Incidence, range, and clinical effect of hemoglobin changes within 24 hours after transradial coronary stenting. Am J Cardiol. 2010;106(2):155-161.

104. Pancholy S, Patel T, Sanghvi K, Thomas M, Patel T. Comparison of door-to-balloon times for primary PCI using transradial versus transfemoral approach. Catheter Cardiovasc Interv. 2010;75(7): 991-995.

105. Arzamendi D, Ly HQ, Tanguay JF, et al. Effect on bleeding, time to revascularization, and one-year clinical outcomes of the radial approach during primary percutaneous coronary intervention in patients with ST-segment elevation myocardial infarction. Am J Cardiol. 2010;106(2):148-154.

106. Hansen ML, Sørensen R, Clausen MT, et al. Risk of bleeding with single, dual, or triple therapy with warfarin, aspirin, and clopidogrel in patients with atrial fibrillation. Arch Intern Med. 2010; 170(16):1433-1441.

107. Karjalainen PP, Porela P, Ylitalo A, et al. Safety and efficacy of combined antiplatelet-warfarin therapy after coronary stenting. Eur Heart J. 2007;28(6):726-732.

108. Sarafoff N, Ndrepepa G, Mehilli J, et al. Aspirin and clopidogrel with or without phenprocoumon after drug eluting coronary stent placement in patients on chronic oral anticoagulation. J Intern Med. 2008; 264(5):472-480.

109. King SB 3rd, Smith SC Jr, Hirshfeld JW Jr, et al. 2007 focused update of the ACC/AHA/SCAI 2005 guideline update for percutaneous coronary intervention: a report of the American College of Cardiology/ American Heart Association Task Force on practice guidelines. J Am Coll Cardiol. 2008;51(2):172-209.

110. Schömig A, Sarafoff N, Seyfarth M. Triple antithrombotic management after stent implantation: when and how? Heart. 2009; 95(15):1280-1285.

111. Lagerqvist B, James SK, Stenestrand U, Lindbäck J, Nilsson T, Wallentin L. Long-term outcomes with drug-eluting stents versus bare-metal stents in Sweden. $N$ Engl J Med. 2007;356(10): 1009-1019.

112. Park SJ, Park DW, Kim YH, et al. Duration of dual antiplatelet therapy after implantation of drug-eluting stents. N Engl J Med. 2010; 362(15):1374-1382

113. Angiolillo DJ, Suryadevara S, Capranzano P, Zenni MZ, Guzman LA, Bass TA. Antiplatelet drug response variability and the role of platelet function testing: a practical guide for interventional cardiologists. Catheter Cardiovasc Interv. 2009;73(1):1-14.

114. Sharma RK, Reddy HK, Singh VN, Sharma R, Voelker DJ, Bhatt G. Aspirin and clopidogrel hyporesponsiveness and nonresponsiveness in patients with coronary artery stenting. Vasc Health Risk Manag. 2009;5:965-972.

115. Breet NJ, van Werkum JW, Bouman HJ, et al. Comparison of platelet function tests in predicting clinical outcome in patients undergoing coronary stent implantation. JAMA. 2010;303(8):754-762.

116. Damani SB, Topol EJ. The case for routine genotyping in dualantiplatelet therapy. J Am Coll Cardiol. 2010;56(2):109-111.

117. Ben-Dor I, Kleiman NS, Lev E. Assessment, mechanisms, and clinical implication of variability in platelet response to aspirin and clopidogrel therapy. Am J Cardiol. 2009;104(2):227-233.

118. Snoep JD, Hovens MM, Eikenboom JC, van der Bom JG, Huisman MV. Association of laboratory-defined aspirin resistance with a higher risk of recurrent cardiovascular events: a systematic review and meta-analysis. Arch Intern Med. 2007;167(15):1593-1599.

119. Krasopoulos G, Brister SJ, Beattie WS, Buchanan MR. Aspirin "resistance" and risk of cardiovascular morbidity: systematic review and meta-analysis. BMJ. 2008;336(7637):195-198.

120. US Food and Drug Administration. FDA Drug Safety Communication: Reduced Effectiveness of Plavix (Clopidogrel) in Patients Who Are Poor Metabolizers of the Drug. Updated 2010 Mar 25. Rockville, MD: FDA; 2010. Available from: http:/www.fda.gov/Drugs/Drug Safety/PostmarketDrugSafetyInformationforPatientsandProviders/ ucm203888.htm. Accessed 2010 Oct 20. 
121. Mega JL, Close SL, Wiviott SD, et al. Cytochrome P450 genetic polymorphisms and the response to prasugrel: relationship to pharmacokinetic, pharmacodynamic, and clinical outcomes. Circulation. 2009;119(19):2553-2560.

122. Gurbel PA, Bliden KP, Antonino MJ, et al. The effect of elinogrel on high platelet reactivity during dual antiplatelet therapy and the relation to CYP2C19*2 genotype: first experience in patients. J Thromb Haemost. 2010;8(1):43-53.

123. Sofi F, Marcucci R, Gori AM, Giusti B, Abbate R, Gensini GF. Clopidogrel non-responsiveness and risk of cardiovascular morbidity. An updated meta-analysis. Thromb Haemost. 2010;103(4):841-848.

124. Friedewald VE, Ram CV, Wesson DE, White WB, Williams GW, Roberts WC. The editor's roundtable: effect of nonsteroidal antiinflammatory drugs on blood pressure. Am J Cardiol. 2010;105(12): 1759-1767.

125. Catella-Lawson F, Reilly MP, Kapoor SC, et al. Cyclooxygenase inhibitors and the antiplatelet effects of aspirin. $N$ Engl J Med. 2001; 345(25):1809-1817.

126. FitzGerald GA. Parsing an enigma: the pharmacodynamics of aspirin resistance. Lancet. 2003;361(9357):542-544

127. Ray WA, Stein CM, Hall K, Daugherty JR, Griffin MR. Non-steroidal anti-inflammatory drugs and risk of serious coronary heart disease: an observational cohort study. Lancet. 2002;359(9301):118-123.

128. Capone ML, Sciulli MG, Tacconelli S, et al. Pharmacodynamic interaction of naproxen with low-dose aspirin in healthy subjects. J Am Coll Cardiol. 2005;45(8):1295-1301.
129. Wilner KD, Rushing M, Walden C, et al. Celecoxib does not affect the antiplatelet activity of aspirin in healthy volunteers. J Clin Pharmacol. 2002;42(9):1027-1030.

130. US Food and Drug Administration. Information for Healthcare Professionals: Concomitant Use of Ibuprofen and Aspirin. Updated 2009 Sep 29. Rockville, MD: FDA; 2006. Available from: http://www.fda gov/Drugs/DrugSafety/PostmarketDrugSafetyInformationforPatients andProviders/ucm125222.htm. Accessed Jun 202010.

131. US Food and Drug Administration. Analysis and recommendations for agency action regarding nonsteroidal antiinflammatory drugs and cardiovascular risk. J Pain Palliat Care Pharmacother. 2005;19(4): 83-97.

132. Scheiman JM, Fendrick AM. Summing the risk of NSAID therapy. Lancet. 2007;369(9573):1580-1581.

133. Li XQ, Andersson TB, Ahlström M, Weidolf L. Comparison of inhibitory effects of the proton pump-inhibiting drugs omeprazole, esomeprazole, lansoprazole, pantoprazole, and rabeprazole on human cytochrome P450 activities. Drug Metab Dispos. 2004;32(8): $821-827$

134. US Food and Drug Administration. FDA Reminder to Avoid Concomitant Use of Plavix (Clopidogrel) and Omeprazole. Updated 2010 Oct 27. Rockville, MD: FDA; 2010. Available from: http://www.fda.gov/Drugs/DrugSafety/ucm231161.htm. Accessed Oct 282010

135. Schafer AI. Antiplatelet therapy. Am J Med. 1996;101(2):199-209.
Patient Related Outcome Measures

\section{Publish your work in this journal}

Patient Related Outcome Measures is an international, peer-reviewed, open access journal focusing on treatment outcomes specifically relevant to patients. All aspects of patient care are addressed within the journal and practitioners from all disciplines are invited to submit their work as well as healthcare researchers and patient support groups. Areas covered will

\section{Dovepress}

include: Quality of life scores; Patient satisfaction audits; Treatment outcomes that focus on the patient; Research into improving patient outcomes; Hypotheses of interventions to improve outcomes; Short communications that illustrate improved outcomes; Case reports or series that show an improved patient experience; Patient journey descriptions or research. 